\title{
O USO DA INTERNET COMO RECURSO PARA PESQUISA
}

\author{
Janice Zanon Piacentini de Souza (PG-UEMS) \\ Raquel Rosan Christino Gitahy (UEMS)
}

\begin{abstract}
Resumo
Este trabalho é o resultado de um estudo bibliográfico visando a refletir e conceituar o uso da internet como mais um recurso metodológico em sala de aula, para auxiliar e despertar no aluno o interesse pelas pesquisas educacionais. Esta nova alternativa apresenta uma série de pontos positivos, pois a internet disponibiliza uma gama de conteúdos diversificados e em tempo real na comunicação com o mundo. Porém, é necessária a conscientização dos perigos que internet pode oferecer em sala de aula pelo uso incorreto por profissionais não qualificados para esta nova tecnologia. Ela abre caminhos para a aquisição de novas experiências que podem conduzir à promoção da cidadania, já que a sociedade é produto de experiências adquiridas através dos tempos. Assim sendo, deve ser utilizada como mais uma ferramenta para resgatar no aluno o anseio pelo saber e, ao mesmo tempo, fazer com que professores repensem suas práticas metodológicas educacionais e reflitam que, por meio do computador, também alcançarão ensino e aprendizagem. A inclusão digital nas escolas é um espaço cujo objetivo é promover e assegurar ao aluno a exposição de suas ideias, e sua interação com o mundo de forma participativa e criativa. $\mathrm{O}$ uso do micro e de todos os demais recursos tecnológicos disponíveis, se colocados como auxiliares estimuladores do raciocínio lógico e da sede e busca de conhecimento e troca de experiências, levará certamente à superação de suas próprias limitações, provocando o desenvolvimento de capacidades cognitivas, ou seja, indiretamente ocorrerá a inclusão na sociedade do mundo digital.
\end{abstract}

Palavras-chave: Tecnologia. Internet. Aluno. Pesquisa.

\section{Introdução}

As escolas brasileiras têm enfrentado grandes problemas nas últimas décadas com a desmotivação no contexto da pesquisa escolar. $\mathrm{O}$ ambiente escolar deve preparar-se para atender a esta nova geração de alunos "navegadores" e usar este artefato - que é a internet - como um chamariz para o processo ensino/aprendizagem, de uma maneira rápida e inteligente. A necessidade de pesquisar e estar informado é um dos pontos principais para que o aluno desenvolva suas habilidades cognitivas e adquira conhecimentos.

A pesquisa escolar é um dos caminhos pelos quais os alunos irá se aproximar da área de produção de conhecimento e, esse canal de ligação entre pesquisa e conhecimento deve ser conduzido pelo professor. Diante desse contexto, se o professor não tiver habilidades e disposição para executar tal atividade, essa relação pesquisa/conhecimento não acontecerá.

\begin{tabular}{|l|l|l|l|l|l|}
\hline Interface da Educ. & Paranaíba & v. 1 & n. 1 & p. 20-31 & 2010 \\
\hline
\end{tabular}


Este trabalho tem como objetivo realizar uma reflexão sobre a importância do uso das novas tecnologias para auxiliar pesquisas em sala de aula. A proposta é dar ênfase à necessidade da inclusão digital e desmitificar a aversão ao computador; demonstrar que a junção entre o universo digital e o uso de recursos tecnológicos como materiais didáticos podem favorecer tanto os docentes como os alunos, para que possam entender e dominar as novas tecnologias e gerarem uma sociedade preparada para a vida real e virtual. Esta preocupação da qualidade de conhecimento, e da busca de informação por meio de recursos tecnológicos, resulta em uma sociedade mais evoluída nos aspectos econômicos, sociais, educacionais e culturais. Se inclusão digital está impressa em nossas políticas educacionais, que ela venha para despertar no aluno o anseio pelo saber, pois futuramente ele será um formador de opinião que atuará efetivamente em vários aspectos na sociedade.

\section{Pesquisar de Forma Diferente}

Possibilitar essa nova forma de pesquisa escolar mediada pela internet na sala de aula, é conduzir para uma nova concepção de fonte de conhecimento que supere a mera cópia do trabalho que o professor elenca para o aluno. Ir até a biblioteca para fazer a pesquisa e, ao chegar lá, a bibliotecária já deixar a página da enciclopédia marcada, preparada para o aluno realizar a cópia, pouco ou nenhum conhecimento real produz.

Assim, que essa nova alternativa - ler/escrever que ultrapassa as paredes das tradicionais bibliotecas - propicie um ato de construção do saber, que promova uma ação educativa transformando o educando em um sujeito leitor-escritor.

Podemos definir pesquisa como uma busca contínua pelo ato do saber, do conhecer, do descobrir. Bagno (2000, p. 17) define pesquisa:

Pesquisa é uma palavra que nos veio do espanhol. Este por sua vez herdou-a do latim. Havia em latim o verbo perquiro, que significava 'procurar; buscar com cuidado; procurar por toda parte; informar-se; inquerir; perguntar; indagar bem, aprofundar na busca'. O particípio passado desse verbo latino era perquisitum. Por alguma lei da fonética histórica, o primeiro $\mathrm{R}$ se transformou em $\mathrm{S}$ na passagem do latim para o espanhol, dando o verbo pesquisar que conhecemos hoje.

O interesse pela pesquisa não deve partir somente da obrigatoriedade do aluno corresponder ao aplicado pelo professor, mas sim, deve ser também o objeto de desejo do professor; um bom professor deve ser um bom pesquisador para poder exigir a participação do

\begin{tabular}{|l|l|l|l|l|l|}
\hline Interface da Educ. & Paranaíba & v. 1 & n. 1 & p. 20-31 & 2010 \\
\hline
\end{tabular}


aluno. É necessário que haja uma interação entre quem aprende e quem ensina, para que aconteça uma troca de conhecimentos significativa em que ambos sejam igualmente recompensados pelo ato de ensinar e aprender.

O site historiaehistoria.com.br nos informa que o ato de pesquisar foi inserido no âmbito escolar nos meados dos anos 70, com a implementação da Lei 5.692 como uma nova opção de restaurar o ensino brasileiro, mas foi utilizada como prática obrigatória em sala de aula; a função do professor era de exigir que o aluno pesquisasse, não como fonte de conhecimento, mas sim, pelo simples ato de cumprir o currículo que a política educacional da época exigia. Segundo Papert (1994, p. 29): “[...] o trabalho escolar é feito apenas porque o planejador de um currículo decidiu que fazer o trabalho moldaria quem fizesse numa forma desejável [...]".

Ao contrário do que a própria política educacional daquela época focava, a internet disponibiliza milhões de informações a uma infinidade de pessoas interligadas ao mesmo tempo e em qualquer lugar do mundo, possibilitando uma série de condições favoráveis como centro de pesquisas. Segundo Leite (2003, p. 82), internet é:

É a maior rede de computadores interligada a milhares de redes menores. Surgiu em 1969 com o objetivo de tornar possível a comunicação entre os pesquisadores de algumas universidades norte-americanas que utilizavam diferentes tipos de computadores e sistemas. Popularizou-se a partir da década de 80 permitindo o acesso individual e comercial.

O ritmo acelerado e a quantidade de informações, que circulam no mundo atualmente pela internet, exige do aluno a capacidade de absorver e selecionar o máximo possível dessas informações. Assim, o professor deve criar critérios metodológicos para produzir uma educação com qualidade, e quem trabalha na área de educação conhece os novos desafios criados pelas mudanças e transformações, que gera nos modos de produção de conhecimento, que são provocados pelo uso da internet e, além de proporcionar formação cultural, ela pode efetivar a implementação da transdisciplinaridade na sala de aula. Assim os alunos desenvolvem suas habilidades cognitivas mediante um novo meio de pesquisa..

Navegar livremente na internet, como uma aranha atravessando sua teia, é, sem dúvida, uma das sensações mais delirantes para o jovem brasileiro. A estrutura de hipertextos na www (WORLD WIDE WEB) é um poderoso engenho de busca de informação, permitindo que o usuário siga sua intuição, utilizando sua própria configuração de inteligência e curiosidade para buscar locais com informação nova e interessante [...]. (OLIVEIRA, 1996, p. 97).

\begin{tabular}{|l|l|l|l|l|c|}
\hline Interface da Educ. & Paranaíba & v. 1 & n. 1 & p. 20-31 & 2010 \\
\hline
\end{tabular}


A escola precisa mudar seu paradigma sobre educação, precisa considerar o aluno como um ser pensante, dotado de habilidades e talentos, com história de vida, com estilos diferentes de representações sociais; são aspectos que devem ser analisados na hora do processo ensino/aprendizagem.

A inclusão digital abre caminhos para a aquisição de novas experiências que podem conduzir à promoção da cidadania, pois a sociedade é produto de experiências adquiridas através dos tempos:

\begin{abstract}
A pessoa que não passa pela experiência da aprendizagem mediada ou a tem insuficientemente ou não apropriada, sofre de privação cultural. É um ser que fica privado de seu direito de existir na familiaridade com sua própria cultura. (MACHADO, 2004, p. 84).
\end{abstract}

Uma integração entre as informações adquiridas por meio do acesso que o computador disponibiliza e a produção de conhecimentos, indiretamente estará formando um aluno com mais possibilidades de contribuir socialmente. De acordo com Schlünzen (2000, p.82), inclusão digital: "É o acesso de direito ao mundo digital, para o desenvolvimento intelectual (educação, geração de conhecimento, participação e criação) e para a capacidade técnica e operacional”.

Mas, para que essas informações adquiridas transformem-se em conhecimento, exige-se do educador uma postura docente que seja empenhada não só com a técnica de ensinar a manusear uma máquina, como também o interesse do educador com o fundamento básico da inclusão digital, que é a integração entre a escola e o contexto social, em que o objetivo maior da educação escolar é a educação para uma vida social. A escola necessita ensinar para seus alunos aquilo que ele vai usar no próprio convívio social. Segundo Lévy (2006, p. 41): "O computador é, portanto, antes de tudo um operador de potencialização da informação [...]”.

$\mathrm{O}$ anseio de um educador é que seus alunos sejam frequentes, atuantes e participativos, mas, é necessário examinar cuidadosamente quais são os métodos utilizados para que isso aconteça em sala de aula.

De acordo com Veiga (1998, p. 51),

[...] a opção do professor por um ensino crítico e transformador somente se concretizará através de uma sistemática de planejar seu trabalho de forma participativa e problematizadora, que ouse dar oportunidade para o aluno reelaborar os conteúdos do saber sistematizado, com vistas à produção de novos conhecimentos.

A escola precisa tornar-se mais atraente e rever métodos de conceitos tradicionais no ensino, mesmo porque, o processo convencional da alfabetização nunca deixará de ser

\begin{tabular}{|l|l|l|l|l|l|}
\hline Interface da Educ. & Paranaíba & v. 1 & n. 1 & p. 20-31 & 2010 \\
\hline
\end{tabular}


fundamental à formação, mas, é necessário mudar o velho conceito de que escola é o lugar de aprender ca ler/escrever. Saviane (2003), nos chama claramente a atenção sobre a especificidade do saber escolar: é o conjunto de conhecimentos, ideias, técnicas, recursos e artefatos. É uma necessidade incorporar a tecnologia como fonte de aprendizagem, e o professor deve ser o mediador nesta nova concepção de ensino. Levar em consideração que a tecnologia é uma importante aliada para o desenvolvimento educacional e que essas informações transmitidas gere mudanças significativas nos atuais métodos de ensino utilizados pelo professor visando a uma reciprocidade com o aluno, dando margem nessa transferência de experiências entre professor/aluno. Ambos agentes do saber e conhecer .

\section{Internet como fonte de pesquisa}

O progresso tecnológico favorece novas técnicas de comunicação e principalmente como fonte de pesquisa no qual, quantidade e variedade de acervos disponíveis na internet, são imensuráveis e podem aprimorar a qualidade de ensino.

Esse enfoque privilegia, em suas reflexões, a noção de que a educação deve adequar o homem à sua época e que isso, na atualidade, corresponde a desenvolver uma educação para o futuro, que tome a seu encargo a orientação das forças que estão amadurecendo e busque preparar as jovens gerações para as tarefas que as esperam ( SAVIANI, 2003, p. $63)$.

Aceitar a internet como fonte de pesquisa educacional é possibilitar aos alunos e professores acesso a conteúdos atuais e com maior rapidez e agilidade. De acordo com Oliveira (1996, p. 97), o acesso à informação deve ser de forma moderna e diversificada:

[...] Informações de natureza textual, imagética e sonora, vindas de todos os cantos do mundo, sobre todos os assuntos imagináveis e disponibilizadas de forma a permitir navegação em várias dimensões (passado/presente/futuro, superficial/regular/profunda, atualizadíssima/corrente/tradicional), [...].

Enquanto uma pesquisa em um acervo tradicional levaria meses, na internet dá-se em questão de minutos; a aquisição de informações é muito maior e em menos tempo, e com resultados mais satisfatórios. Segundo Bagno (2000, p.48): “[...] Hoje em dia, não sei o que seria da minha vida de tradutor se não pudesse recorrer a ela. Já obtive informações ali sobre o Brasil que nenhum livro impresso por aqui me deu [...]”. Estas e tantas outras praticidades não querem dizer que deixarão os alunos preguiçosos ou com lentidão de raciocínio.

\begin{tabular}{|l|l|l|l|l|c|}
\hline Interface da Educ. & Paranaíba & v. 1 & n. 1 & p. 20-31 & 2010 \\
\hline
\end{tabular}


O importante aqui é que a rapidez de execução se faz muito significativa, pois o aluno pode direcionar suas habilidades cognitivas em outros campos de pesquisa. $\mathrm{O}$ simples fato de o aluno ir até uma biblioteca, pegar um livro e manusear, não é garantia de que irá adquirir mais conhecimento, isto requer uma vontade voluntária muito pessoal de cada aluno. Disponibilizar tempo para que os alunos naveguem pela rede é um dos meios para preparar os jovens a participarem de uma sociedade voltada para um mundo que não para de evoluir, e o sistema escolar precisa unir todos os recursos disponíveis, direcionando os alunos para que possam adquirir experiências e contribuírem como sujeitos produtivos, tanto no contexto social, quanto no mercado de trabalho.

Por que não considerar a internet como suporte e instrumento cultural na área pedagógica? Segundo Costa (2006, p. 23):

\footnotetext{
A Internet oferece, portanto, uma variedade imensa de tipos de textos que podem ser lidos ou escritos/produzidos, ou seja, novos gêneros (hiper)textuais que estão presentes nesse novo espaço cultural, podem ser lidos ou construídos com os imensos recursos técnicos que o computador coloca à disposição [...].
}

Além do fato de estar pesquisando, navegar pela internet é a descoberta do mundo por meio dos hipertextos, rompendo distâncias geográficas, sociais e a exploração de todos os recursos disponibilizados pela dinâmica da interação com o novo, com o que há de mais atual, permitindo descobrir o desconhecido. Nunca uma biblioteca tradicional estará atualizada com tanta rapidez como na internet, e essa flexibilidade de acesso passa a ter um valor cultural muito significativo, pois pode proporcionar aos alunos e professores uma comunicação com seus conterrâneos, trocando informações sobre descendências de origem, modo de viver, hábitos culturais, tradições. Essa comunicação eletrônica pode auxiliar na valorização cultural de cada país, “[...] uma diversidade que abrange traços histórico-culturais, socioeconômicos e até geográficos.[...] muito trabalho deverá ser feito para que se desenvolva a tolerância às diversidades, o respeito a outros valores e culturas" (OLIVEIRA, 1996, p. 122-123).

A digitalização dos hipertextos possibilita uma navegação mais rápida e eficaz em meio a um gama de informações com recursos disponíveis dos mais variados tipos, formatos e fontes. Além de que, este recurso, não inviabiliza a utilização de outros recursos tais como: jogos, atualidades, música, leitura de revistas em quadrinhos, que tanto podem ser virtuais como em suportes tradicionais.

\begin{tabular}{|l|l|l|l|l|l|}
\hline Interface da Educ. & Paranaíba & v. 1 & n. 1 & p. 20-31 & 2010 \\
\hline
\end{tabular}


[...] a digitalização introduz uma pequena revolução copernicana: não é mais o navegador que segue as instruções de leitura e se desloca fisicamente no hipertexto, virando as páginas, transportando pesados volumes, percorrendo com seus passos

biblioteca, mas doravante é um texto móvel, caleidoscópio, que apresenta suas facetas, gira, desdobra-se à vontade diante do leitor ( LÉVY, 1996, p. 44).

Incentivar a pesquisa para desenvolver no aluno o hábito de pensar, refletir, questionar e argumentar usando recurso tecnológico é fundamental para que a principal função da internet seja a de objeto de estudo, e não uma fábrica de inteligência artificial. É muito importante um acompanhamento metodológico de conscientização sobre o famoso copiar e colar:

A tentação da cópia no mundo da nova mídia é enorme, porque a profusão de informação atinge patamares de verdadeira inundação incontrolável. Por causa disso, muitos alunos que imaginam "pesquisar" na Internet não vão além de acumular pedaços de textos ou imagens, tendo como trabalho apenas navegar para coletar dados, sem se preocupar em tornar-se sujeito de conhecimento reconstruído ( DEMO, 2003, p.79).

Outra faceta que a internet disponibiliza é a possibilidade de publicar os textos criados pelos próprios alunos; esse recurso pode ser usado pelos educadores como incentivo de divulgarem os trabalhos de sua própria autoria, ou seja, cria a oportunidade de editar textos ou trabalhos desenvolvidos dentro da própria escola para que toda a comunidade virtual tenha acesso.

A educação precisa se desenvolver, adaptar, inovar e, principalmente, se atualizar, para acompanhar o desenvolvimento do ser humano. Podemos perceber que na evolução da tecnologia, a educação é um dos campos da sociedade que menos acompanhou esse progresso, entretanto, o que se sabe é que é na escola que o indivíduo é formado na concepção de sociedade. A escola há muito deixou de ser um lugar onde só se ensinava a ler e a escrever; hoje a escola é considerada como o berço do saber/aprender e, a internet pode ter um papel fundamental nessa função, devido a sua riqueza de conteúdo. Ela abre caminhos enquanto forma de pesquisa, pois edifica pontes para diminuir as distâncias físicas e sociais que separa o aluno do ambiente em que vive e o do conhecimento de outras culturas e até mesmo da realidade mundial.

Navegando na rede, não estaremos, portanto, apenas nos apropriando de um novo instrumental técnico revolucionário ou de novos códigos sonoro-visuais ou gráficoauditivos comunicativos para escrever e ler, mas, sim, construindo um novo objeto conceitual mediado por novos tipos de interação lingüística, social e cultural. (COSTA, 2006, p. 26).

Um dos aspectos negativos ao focalizar a importância da pesquisa por meio da internet é que ainda existem pessoas sem qualificação para usufruir deste tipo de recurso tecnológico, e é

\begin{tabular}{|l|l|l|l|l|l|}
\hline Interface da Educ. & Paranaíba & v. 1 & n. 1 & p. 20-31 & 2010 \\
\hline
\end{tabular}


fato que, ou acompanhamos a tendência positiva gerada pela evolução, ou ficamos à mercê da metamorfose natural da humanidade, caminhando a passos lentos, esperando que algum milagre aconteça. Segundo Lévy ( 1996, p. 118):

[...] Ou acompanhamos as tendências mais positivas da evolução em curso e criamos um projeto de civilização centrada sobre os coletivos inteligentes: recriação do vínculo social mediante trocas de saber, reconhecimento, escuta e valorização das singularidades, democracia mais direta, mais participativa, enriquecimento das vidas individuais, invenção de formas novas de cooperação aberta para resolver os terríveis problemas que a humanidade deve enfrentar, disposição das infra estruturas informáticas e culturais inteligentes.

A educação usando pedagogicamente a internet como um recurso visando a levar o aluno a adquirir uma aprendizagem pessoal mais rica e ao mesmo tempo criativa; e como também, ao permitir que o conhecimento diversificado ultrapasse os livros didáticos e as salas de aula, proporcionará ao aluno uma formação com autonomia para a emancipação com coerência, formando assim um sujeito que requer muito mais que ser um agente passivo no contexto escolar, mas sim um indivíduo que queira partilhar as experiências vividas com toda sociedade, sujeito agente do seu aprender e fazer.

Para que o computador em sala de aula? O que podemos fazer com o computador no contexto educacional? Podemos ensinar por meio do computador? São várias as questões que atormentam os profissionais da educação. As respostas só serão encontradas a partir do momento em que cada proposta for colocada em prática juntamente com a dedicação do professor envolvido no caso. O mais importante é que todos os envolvidos se dediquem e aceitem o desafio de forma positiva. A elaboração de um projeto pedagógico é necessário para que a escola atinja seus objetivos, assim evitará uma possível frustração ao se deparar com muitos erros.

\footnotetext{
O uso coletivo em sala de aula é totalmente diferente: em geral ocorre com a mediação do professor, normalmente em atividades disciplinares, e corresponde à utilização de materiais didáticos escolhidos e validados, preparados e trazidos pelo professor, integrados em seus planos de aula. Trata-se de uma observação orientada, utilizada em geral como apoio às aulas expositivas, e na qual se utiliza principalmente materiais audiovisuais [...] pode produzir grandes vantagens em razão da possibilidade de acesso à informação buscada e à interatividade que torna a atividade mais dinâmica. (BELLONI, 2003, p. 72, grifos do autor).
}

A troca de informações e a interatividade entre estudantes e pesquisadores por meio de redes informáticas favorece o desenvolvimento de pesquisas científicas facilitadas pelo acesso rápido e fácil de adquirir informações, dados estatísticos atualizados, imagens de satélites que são

\begin{tabular}{|l|c|c|c|c|c|}
\hline Interface da Educ. & Paranaíba & v. 1 & n. 1 & p. 20-31 & 2010 \\
\hline
\end{tabular}


instantâneas, e outras vantagens que podem tornar a pesquisa mais completa, com resultados satisfatórios e com este incentivo podem surgir novos pesquisadores.

Nada vai adiantar possuir/utilizar recursos tecnológicos se não houver uma pedagogia inovadora que possibilite o uso da tecnologia como fonte reflexiva e que condicione o aprendiz a uma nova forma de integração com o conhecimento e, cabe lembrar, que o ambiente escolar também deve se adequar para essa nova concepção de ensino/aprendizagem, pois as tecnologias estão presentes no universo da vida cotidiana dos jovens. As informações que vinham sendo transferidas de séculos a séculos por meio de recursos como a pedra, papiro, papel, giz, é hoje transmitida por meio de bits, códigos digitais, mensagens virtuais, e-mails; essa evolução tecnológica proporciona conhecimentos que também podem ser utilizados como recurso educacional no ambiente escolar.

Romper o espaço físico das atividades pedagógicas para o espaço virtual, é abrir as salas de aula para o mundo, onde o ambiente educacional proporcionado pelas novas tecnologias pode ser ilimitado, proporcionando uma infinita produção de conhecimento. De acordo com Almeida ( 2003, p. 208):

[...] Rompe-se assim com a limitação espaço-temporal da aula, o que possibilita a abertura da sala de aula e dos espaços pedagógicos para o mundo, bem como a integração das organizações educacionais com os demais setores da atividade humana que constituem espaços produtores de conhecimento.

Se podemos ensinar, independente do recurso que vai ser utilizado para que haja aprendizagem, e desde que estes recursos sejam coerentes e em condições de transmitir e construir o conhecimento de forma participativa do aluno, por que não viabilizar esse método de ensino? Se o aluno tem anseio pelo saber, pela cultura, pelo intelecto, ele - aluno - vai aproveitar cada momento dispensado de seu tempo para realmente aprender, se o aluno desejar aprender vai buscar informações para orientar-se, pesquisar, interagir e dedicar-se ao estudo.

Aprender depende também do aluno, de que ele esteja pronto, maduro, para incorporar a real significação que essa informação tem para ele, incorporá-la vivencialmente, emocionalmente,. Enquanto a informação não fizer parte do contexto pesssoalintelectual e emocional - não se tornará verdadeiramente significativa, não será verdadeiramente. (MORAN, 2003, p. 30).

Mudanças, adaptações, transformações, é o que a sociedade exige cada vez mais e que o "mundo" da escola seja recriado e adaptado para seus novos aluno. Alunos estes, que já saem de suas casas com um conceito pré-determinado de que lá fora existe um ambiente em que a cultura

\begin{tabular}{|l|l|l|l|l|c|}
\hline Interface da Educ. & Paranaíba & v. 1 & n. 1 & p. 20-31 & 2010 \\
\hline
\end{tabular}


e o conhecimento devem ser adquiridos por meio de um processo que dê continuidade cultural ao que já traz consigo. Ao se descobrir como sujeito da transformação do mundo, o homem qualifica-se como agente de cultura. Por isso, o processo de busca na educação implica cultura. Aquilo que aprendemos ontem, pode ser (re)aprendido hoje, mas de uma forma renovada, por outros meios, por outros métodos, por isso que a cultura está sempre em transformação, estamos a cada dia em construção por meio de um processo natural de evolução. A internet já está inserida no nosso contexto cultural, desta forma é preciso colocar em nosso meio educacinal e aproveitá-la da melhor forma possível.

Há programas na internet específicos para pesquisas, que podem auxiliar em trabalhos escolares, científicos com muita propriedade e fundamentação, são sites que disponibilizam temáticas em vários aspectos em questões de segundos, facilitando e ao mesmo tempo direcionando informações específicas e atualizadas.

O Google é um dos programas mais conhecidos no mundo virtual, e recentemente lançou mais uma novidade: ao acessar o Google Earth permite visualizar mapas antigos e até mesmo o globo terreste por meio de uma das tecnologias mais modernas que é a transmissão de imagens por satélite e em tempo real.

Quanto mais viajamos, no planeta ou nos livros, na Internet ou na sociedade em torno de nós, mais se abre nosso espírito. A comunicação entre os homens desdobra-se, reflete-se, multiplica-se na interconexão entre as informações lentamente dispostas nas bibliotecas que explodem hoje no ciberespaço. (LÉVY, 2003, p. 48).

No site http://www.bn.br/bndigital do Ministério da Cultura há uma biblioteca digital com acervos históricos digtalizados para pesquisas escolares e científicas.

Outro site com indicações de links que podem auxiliar nas pesquisas escolares http://www.sobresites.com/pesquisa/pesquisa.htm, cito alguns: http://www.webciência.com - Concentrado em ciências, geografia e saúde, o site permite ao internauta fazer a sua busca no índice temático ou pelo mecanismo de busca. Traz conteúdo atualizado, informando as últimas descobertas científicas.

http://www.tvcultura.com.br/aloescola/index.html - O site reúne todo o conteúdo de diversos programas produzidos pela TV e Rádios Cultura. Excelente fonte de pesquisa e diversão, em um site muito bem feito.

Interface da Educ.

Paranaíba

V. 1

n. 1

p. 20-31

2010 
http://www.bibvirt.futuro.usp.br/ - Aqui o aluno encontra vários recursos de apoio para trabalhos escolares, como textos organizados por disciplinas e obras da literatura brasileira em formato PDF. Utiliza parte do material didático do Telecurso 2000.

Destaque para a vozoteca, acervo de gravações de discursos históricos.

www.domíniopublico.gov.br - O "Portal Domínio Público", lançado em novembro de 2004 (com um acervo inicial de 500 obras), propõe o compartilhamento de conhecimentos de forma equânime, colocando à disposição de todos os usuários da rede mundial de computadores uma biblioteca virtual que deverá se constituir em referência para professores, alunos, pesquisadores e para a população em geral.

http://www.periodicos.capes.gov.br - Professores, pesquisadores, alunos e funcionários de 268 instituições de ensino superior e de pesquisa em todo o País têm acesso imediato à produção científica mundial atualizada por meio deste serviço oferecido pela CAPES. Portal.periodicos. CAPES oferece acesso aos textos completos de artigos selecionados de mais de 12.661 revistas internacionais, nacionais e estrangeiras, e 126 bases de dados com resumos de documentos em todas as áreas do conhecimento. Inclui também uma seleção de importantes fontes de informação acadêmica com acesso gratuito na internet.

http://bdtd.ibict.br/ - A BDTD (Biblioteca Brasileira de Teses e Dissertações) objetiva integrar, em um só portal, os sistemas de informação de teses e dissertações existentes no país, assim como disponibilizar em todo o mundo, via internet, o catálogo nacional de teses e dissertações em texto integral, também acessível via Networked Digital Library of Theses and Dissertatio (NDLTTD). O portal tem como proposta, além de disponibilizar gradativamente, para consulta ou download, a produção nacional de teses e dissertações, oferecer aos usuários produtos e serviços integrados capazes de proporcionar aumento significativo ao impacto de suas pesquisas.

\section{Considerações Finais}

Conclui-se portanto que a internet em relação à educação é um meio viável para a informação e para a produção do conhecimento, pode e deve ser utilizada como mais um instrumento de recurso didático em sala de aula para viabilizar as pesquisas e uma nova forma de educar por meio de mais um recurso tecnológico, os quais irão romper todas as barreiras geográficas em poucos segundos. A pesquisa pela internet por ser de forma interativa,

\begin{tabular}{|l|l|l|l|l|l|}
\hline Interface da Educ. & Paranaíba & v. 1 & n. 1 & p. 20-31 & 2010 \\
\hline
\end{tabular}


empolgante, dinâmica, rápida e diversificada em várias áreas, auxilia o aluno no desenvolvimento da aprendizagem e ao mesmo nas descobertas de diferentes culturas e interação no mundo em que vive.

Não existem métodos ou meios corretos para usar o computador em sala de aula, deve-se verificar qual é o objetivo que o professor quer atingir com o seu uso. Para fazer com que o uso de tecnologia surta efeitos positivos são necessários que teoria e prática caminhem concomitantemente, estratégias adequadas se fazem necessárias para que haja uma interação com o conteúdo e o modo de aplicação.

Se somos produtos da nossa própria cultura, por que não desenvolver situações que provoquem mudanças no comportamento humano? Cabe a nós educadores sermos os protagonistas dessa revolução tecnológica, e mudarmos os conceitos pré-educacionais existentes e usar da ética para colocar em prática a verdadeira educação; ensinar a aprender e aprender ao ensinar.

\section{Referências}

ALMEIDA, M. E. B. de. Educação, ambientes virtuais e interatividade. In: SILVA, M. (Org.). Educação online. São Paulo: Edições Loyola, 2003.

BAGNO, M. Pesquisa na escola: o que é e como se faz. 5. ed. São Paulo: Loyola, 2000.

BELLONI, M. L. Educação a distância. 3. ed. Campinas, SP: Editora Autores Associados, 2003.

COSTA, R. S.; FREITAS M. T. de A. (Org.). Leitura e escrita de adolescentes na internet e na escola. 2. ed. Belo Horizonte: Autêntica Editora, 2006.

DEMO, P. Instrucionismo e nova mídia. In: SILVA, M. (Org.). Educação online. São Paulo: Edições Loyola, 2003.

LEITE, S. L. et al. (Coord.). Tecnologia educacional. Petrópoles, RJ: Editora Vozes, 2003.

LÉVY, P. O que é virtual? Tradução Paulo Neves. São Paulo: Editora. 34, 1996.

34,2003

A conexão planetária: o mercado, o ciberespaço, a consciência. 2. ed. São Paulo: Editora

MACHADO, L. R. de S. A educação e os desafios das novas tecnologias. In: FERRETTI, C. J. (Org.). Novas tecnologias, trabalho e educação: um debate multidisciplinar. 8. ed. Petrópolis, RJ: Vozes, 1994.

\begin{tabular}{|l|l|l|l|l|l|}
\hline Interface da Educ. & Paranaíba & v. 1 & n. 1 & p. 20-31 & 2010 \\
\hline
\end{tabular}


MORAM, M. J. Contribuições para uma pedagogia da educação online. In: SILVA, M. (Org.). Educação online. São Paulo: Edições Loyola, 2003.

OLIVEIRA, B. V. de (Org.) . Informática em psicopedagogia. São Paulo: Editora SENAC, 1996.

PAPERT, S. A máquina das crianças: repensando a escola na era da informática. Tradução Sandra Costa. Porto Alegre, RS: Artes Médicas, 1994.

SAVIANE, N. Saber escolar, currículo e didática problemas da unidade conteúdo/método no processo pedagógico. 4. ed. rev. e ampl. Campinas/SP: Autores Associados, 2003.

SCHLÜNZEN, E. T. M. Mudanças nas práticas pedagógicas do professor: criando um ambiente construcionista contextualizado e significativo para crianças com necessidades especiais físicas. 240f. 2000. Tese (Doutorado em Educação) - PUC/SP, São Paulo, 2000. Disponível em:

<http://sbie2004.ufam.edu.br/anais_cd/anaisvol2/WS_Educacao_Especial/WSEE_T01.pdf >. Acesso em: 26 nov. 2008.

VEIGA, A. P. I. Didática: uma retrospectiva histórica. In: LOPES, A. O. et al. Repensando a didática. 13. ed. Campinas, SP: Papirus, 1998. 